\title{
Card from the President: Happy Mother's and Father's Day!
}

It is customary during the late spring in the United States to set aside two Sundays, one in May and one in June, to honor mothers and fathers, respectively. Inspired partly by a family-values tradition and partly by the floral and greeting card industries, many of us take time during this season to reconnect with our parents, or graciously provide the opportunity for our children to do so. During this time, it is appropriate to reflect on how our chosen profession relates to and affects our family relationships.

Whether in industry, academics, or government, much of the actual labor of a materials-oriented job can be fit around family obligations more easily today than one could have imagined a generation ago. Library searching can be done from a laptop at the kitchen table at the rate of hundreds of citations per hour, rather than in remote megalibraries where heavy bound volumes are lugged around for one reference at a time. Experiments can be set for automated data acquisition at predefined times without human intervention. Student assignments and questions can be managed on-line; indeed, for better or worse, many students seem to prefer that these days. Even conference calls can be taken at home, without a special trip to the office. Of course, it is important that all of these telecommuting activities be arranged so that there is really a net increase in family interaction, rather than additional disruption.

There are certainly issues in materials science that diminish its family-friendliness. As materials engineering becomes more entrepreneurial, there seems to be no alternative to uninterrupted night and weekend work to stay ahead of the competition. Government jobs and MRS Meetings themselves require an everincreasing amount of travel away from the home base. The limited number of locales that support major materials efforts limits options for two-career couples, which these days covers many early-career scientists. The issue of the tenure clock coinciding with prime childbearing and child-rearing years applies to academic materials scientists, as it does almost universally to professors in many other fields. The increased responsibility that comes with seniority often hits just as children are becoming adolescents who demand increased intellectual and emotional attention, even though they are no longer infants having trouble sleeping through the night. In this

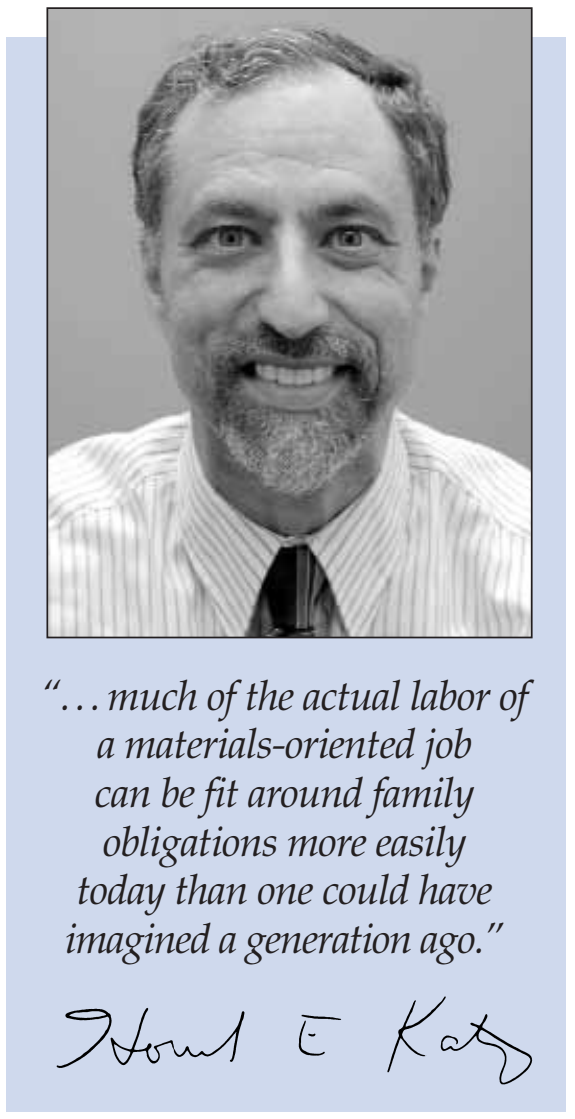

era of geographically dispersed families, the support of elderly relatives is an additional demand on time and effort.

Many of these problems would be ameliorated if the value proposition in materials research were better focused on the quality of one's ideas, rather than the career path and the absolute number of hours worked that led to them. We owe it to our families to lessen the grueling, dues-paying aspects of materials research: the number of pages that have to be written, the number of meetings at which repetitive information needs to be presented, the number of times one needs to argue one's point in order to secure funding, and such. Some of the remedies are structural, and many universities and companies have shown great sensitivity in modifying promotion calendars and work schedules to accommodate the demands of families. The collaborative nature of materials research can help spread the load of projects among multiple participants, and so long as the contribution of each group member is duly recognized, collaboration should be a net plus for families. Child-care facilities and elder-care plans, many sponsored by employers, have advanced considerably since the time when my own children were infants and I had to shiver in line before a January dawn to ensure that they would have spots in the only local child-care facility.

Working in materials means it is often possible to explain to our families quite a bit of what we are doing. We are all familiar with the basic classes of materials (metals, plastics, ceramics, glass, cement) and how they act (conduct heat, carry electricity, offer mechanical protection, light up). Most people, even children, have cooked something, made a clay sculpture, or looked under a magnifying glass. Jewelry is a fairly universal gift for Mother's Day and other occasions, and MRS actually runs symposia on topics such as diamond, opals, and sapphire (often including gold contacts!). Because of the many analogies between what materials investigators do in a lab and people's everyday experiences, our work need not be as mysterious as that of, for example, abstract mathematicians and gene-splicers. A rewarding career adds both intellectual stimulation and lifestyle opportunities to families. When something works really well, we can share the victorious feeling with our families as readily as can champion athletes.

Something significant that we can do to ease the stress on our families is to grow the materials field. The more university materials departments that stay strong, the less pressure there will be on their members and the more location options there will be for families that include materials researchers. The greater the contribution that we can make to societal priorities, the more likely that governments will support their own research facilities. The more commercial success that we can realize from materials innovations, the more accommodating companies will be to their research staff and their families. Even though the growth process may be stressful in the short run, the result should be a net long-term plus for families. Any ideas about how MRS could make this process more familyfriendly would be welcomed.

Above all, when a great materials idea has an impact somewhere, let us tell our families, our friends, and the public. We will be doing many parents and children a favor.

HOWARD E. KATZ 2004 MRS President 